Demirel, H. Ç., Volker, L., Leendertse, W., \& Hertogh, M. (2019). Dealing with Contract Variations in PPPs: Social Mechanisms and Contract Management in Infrastructure Projects. Journal of Construction Engineering and Management, 145(11), 04019073. doi:10.1061/(ASCE)CO.19437862.0001714

\title{
Dealing with Contract Variations in PPPs: Social Mechanisms and Contract Management in Infrastructure Projects
}

iD Hatice Çiğdem Demirel; (D) Leentje Volker, Ph.D.; Wim Leendertse, Ph.D.; and Marcel Hertogh, Ph.D.

\begin{abstract}
Variations are inevitable in public-private partnerships (PPP), due to the extensive duration of these contracts and the dynamic environment in which PPPs are usually implemented. Changes may lead to variations in the contract and consequently adverse reactions by partners. For the social and financial viability of the project, it is important to have mechanisms that can actively deal with variations that occur during the project life cycle. However, formal contracts with standardized project procedures do not always offer effective ways to cope with potential project dynamism. This paper presents the results of an in-depth case study into the modus operandi of a large-scale PPP infrastructure project with regard to variations in the realization phase. It was found that variations in infrastructure projects could not be dealt with solely through the formal contract rules, but that additional social mechanisms between the public commissioners and contracted companies were needed. Changes and contractual mechanisms are extensively discussed in project management literature. Also, the use of social mechanisms - complementary to the formal contract rulesis stressed. However, the literature offers little evidence about how these dealing mechanisms work in practice. This study reflects a real-life practice in responding to variations in a PPP and presents different ways in which various mechanisms, such as contract provisions, human relationships, organizational structure, digital tools, professional knowledge, and actor competences are interactively employed by project managers to deal with variation. General conclusions are drawn about the mechanisms observed, which may be applicable in the coordination of future interaction in public and private collaborations.
\end{abstract}

\section{Introduction}

A public-private partnership (PPP) is a delivery method frequently used to enhance the economic and societal value of public infrastructure projects. In a PPP project, a private party or consortium is granted a concession to finance, build, and operate a public project and to provide the corresponding product or service and collect ensuing revenues (Xiong and Zhang 2014). The PPP approach may increase the economic value of infrastructure outputs because 
management by a private entity can bring important efficiency gains to the public authority body in question (Liu et al. 2014; Iossa 2015). However, in the case of unexpected events, a project can suffer high-profile failures. Long-term arrangements (usually around 2530 years) increase exposure to changing circumstances during the life cycle of a project. According to Taleb (2008), unexpected events or "black swans" are, therefore, a fact of life. Such events can, however, also alter the financial balance of the relationship that was assumed by each party upon signing of the partnership agreement, making the agreement sensitive from a commercial or financial perspective (Mandri-Perrot 2009). Breaking a PPP contract can be expensive, and counterparties can suffer if early termination takes place (Liu et al. 2017). Scholars in PPP emphasize that when PPP projects encounter unforeseen risk events (e.g., Cruz et al. 2014), the parties should conduct renegotiations and attempt to take steps to resolve the imbalance rather than seeking early termination of the contract (Song et al. 2018).

Renegotiations usually arise because of the inadequacy of the contract to address contingencies (Cruz et al. 2014). According to Domingues and Zlatkovic (2015), current PPPs are controlled by a rigid contractual structure. Scholars agree that there are still research gaps in the fields of flexible or adaptive contracting regarding PPPs. For example, Neto et al. (2016) and Cui et al. (2018) believe that the interest in more dynamic contracting will develop into a key research area. This is partly due to the adverse effects of variation as experienced in current practice. Related to this, there is also an ongoing discussion concerning whether PPP procurement and contracts deliver the promised infrastructure project outputs or value for money (e.g., National Audit Office 2018).

Given these concerns, there is a need for the appropriate design of contracts and for procurement methods to be able to adapt to uncertainty during the project life cycle, whether a PPP is involved or not. Thus, public and private interactions need mechanisms to coordinate their future partnerships under changing circumstances. In this paper, we review practices in a large PPP infrastructure project during its realization phase to identify and discuss mechanisms that are used in practice dealing with variations. We will call these mechanisms "dealing mechanisms": a constellation of elements and/or activities that can be used by partners to adapt an initial agreement under variation. Dealing mechanisms are essential to coordinate PPPs under contract variations, ensuring that the contract adequately governs the parties' relationship over the term of the contract and that both parties maintain the associated benefits.

Changes and contractual mechanisms are extensively discussed in project management literature. Also, the use of social mechanisms-complementary to the formal contract rules-is stressed. However, the literature offers little evidence about how these dealing mechanisms work in practice. The primary aim of the study is to achieve a better understanding of the range and elaboration of different contractual and noncontractual mechanisms in the practice of PPPs, and their mutual relationship and interaction. The study thus starts from the following research question: What mechanisms to deal with variation are used in practice for infrastructure projects additional to the formal contract rules and how are they operationalized?

This paper first describes general experiences from previous research on dealing with variations in construction projects from relevant recent literature, and identification of mechanisms currently used in the PPP infrastructure sector are identified. The following "Results" section presents the results of an in-depth case study looking at the modus operandi 
of a large-scale PPP infrastructure project with regard to dealing mechanisms employed in the realization phase. The case reflects real-life practice in a PPP project and reveals how various dealing mechanisms are interactively employed in an actual contract under variation. It is concluded that noncontractual mechanisms are especially required for PPP coordination providing the necessary additivity to ex-ante agreed formal contracts. Based on the results, conclusions and implications for both researchers and practitioners are then formulated with respect to setting up and improving interaction between public and private parties in the context of infrastructure projects.

\section{Dealing with Variations in Contracts Need for Contract Adaptability}

Large infrastructure projects are often characterized as complex, nonlinear, and dynamic processes (Khan et al. 2016) that include specific uncertainties and interdependencies among a large number of stakeholders (Klijn and Koppenjan 2016). Increased stakeholder involvement may create more interaction, and consequently more unpredictability and risks. When outcomes become harder to predict and are spread over a longer period, projects are more difficult to define ex ante and become more vulnerable to variation (Brown et al. 2015; Xiong et al. 2018). According to Shrestha et al. (2018), uncertainties may even be magnified.

In the context of PPPs, many scholars address the fact that contracts have to be dynamic or adaptive to potential challenges and should provide the possibility to renegotiate. Spiller (2018), for example, stated that public contracts are generally inflexible when faced with uncertainties and, therefore, always require renegotiation during execution. According to other scholars (e.g., Cruz et al. 2014; Hart 2017; Sarmento and Renneboog 2016; Xiong and Zhang 2014) the reason for renegotiations is mostly incompleteness because of the inability to foresee all possible future events. The literature describes several mechanisms that have been introduced to deal with this kind of flexibility (Domingues et al. 2015; Javed et al. 2014). Cruz and Marques (2013) proposed to divide a PPP infrastructure contract into two components: a long-term concession (30 years) for building and maintaining infrastructure and an accompanying short-term contract (10 years) for managerial services. Xiong and Zhang (2016) suggested a renegotiation model that enables governments to compare different measures in the case of variation, such as toll adjustment, contract extension and annual subsidy or unitary payment adjustment, and a possibility to suggest a more suitable combination in renegotiation. Domingues and Zlatkovic (2015) proposed the idea of using SWOT (strengths, weaknesses, opportunities, threats) analysis as a tool to agree in more contractual flexibility. They suggest regularly analyzing potential benefits that could be captured and pitfalls that could be avoided and using this analysis for ongoing mutual agreement. Mouraviev and Kakabadse (2015) presented ways to reduce government overregulation (e.g., bureaucratic tariff setting and excessive procurement restrictions) to achieve more "action room" and thus greater flexibility in the management of PPPs.

On the national level, many countries have developed standardized PPP contracts, along with guidance manuals. For example, the Standardisation of PF2 Contractsissued by HM Treasury (2012) in the United Kingdom, the Dutch DBFM Model for Infrastructures issued by Rijkswaterstaat (2014), and the 'Standard Form Public Private Partnership Project Agreement in New Zealand (New Zealand Government, The Treasury 2013). These standards allow for renegotiation under changing circumstances. According to the Standardisation of 
PF2 Contracts, a variation protocol is to be put in place as an appropriate change dealing process, in combination with transparency in the pricing of the change. Standardized contract versions generally include changes proposed by the contracting authority and changes proposed by the private party. Most PPP contracts recognize a right of the contracting authority to propose changes to the terms of the contract (including the agreed terms of the asset's design, construction, operation, and maintenance) and that the private partner is entitled to relief and/or compensation for the consequences of complying with those changes (e.g., Eurostat 2016). If renegotiation is initiated, the public and private partners will negotiate on which measures should be taken to compensate for any loss by the concessionaire, such as debt service coverage ratio, loan life coverage, internal rate of return, and revenues (Xiong and Zhang 2016).

\section{Dealing Mechanisms for Contract Adaptability}

Brown et al. (2015) identify two interrelated categories to deal with uncertainty in complex projects: contract rules and relationships. They argue that, rather than one all-encompassing ex-ante detailed contract, the contract governance should be based on a more general formal contract and additional informal arrangements based on mutual relationships (Brown et al. 2015). Earlier, Ling et al. (2014) discussed that relational contacting is based on cooperative approaches, such as partnering, alliancing, joint venturing, long-term contracting, joint risksharing mechanisms, and integrated project delivery, where formal contracts spell out the rights, responsibilities, and liabilities of the parties concerned.

Many studies (e.g., Ling et al. 2014; Xiong and Zhang 2016) have confirmed that collaborative relationships are an important addition to formal contracts, and that they can facilitate the solution to an issue or problem at hand. Related to this, Zou et al. (2014) found that the commitment of senior executives and the integration of the different divisions and multidisciplinary teams were critical success factors in PPPs. Additionally, Mistarihi et al. (2012) discussed the need for PPP managers to be knowledgeable and qualified to manage the social, constructional, operational, and financial aspects of PPP projects. For a PPP setting, they stress the importance of interpersonal skills, the skill of "scoping in/out," conceptual skills, project management skills, and communication and coordination skills.

Several scholars have focused on mechanisms that allow constant adaptation to potential challenges in the delivery of infrastructure projects. For example, Hertogh and Westerveld (2010) claimed that the success of large and complex infrastructure projects is determined by five factors: a higher order of cooperation, meaning that stakeholders in the system use their cooperative capacities to align their interests in such a way that they produce system outputs that are mutually beneficial; project champions; competent people making the difference; capability to find unique management solutions; and using windows of opportunity.

Kumaraswamy and Rahman (2006) considered working in teams as a form of cooperation and discussed how effective and successful teams can generate benefits in complex projects. They found that teams generate a wider range of ideas than individuals working alone. Teams can respond to change more effectively, since improved trust and communication will help a team to gain greater clarity in expressing ideas through group discussion. Additionally, it has been argued that (Xiong et al. 2018) increased information availability between the actors in projects contributes to responsiveness. 


\section{Research Approach Single Case Study}

Because of the complex and uncertain nature of large infrastructure projects, there is a need to be able to deal with variations. In the literature, several dealing mechanisms are identified, such as standardized contracts with clauses that provide for flexible agreements, but also more social-relational solutions, such as increasing teamwork. However, there is little evidence about how these dealing mechanisms work in practice. Yin (2014) writes that a case study can contain either a single study or multiple studies. The case study method explores a real-life, contemporary bounded system (a case) or multiple bounded systems (cases) over time, through detailed, in-depth data collection involving multiple sources of information and reports a case description and case themes (Creswell 2013). According to Creswell (2013), it is not primarily aimed to analyze cases, but to explore a setting in order to understand it. It makes the researcher have a deeper understanding of the exploring subject (Gustafson 2017).

This paper presents a real-life case study to examine which mechanisms are applied in practice and how they are used in a project context.

A single case approach is not uncommon in studies of complex project environments. For example, Cruz and Marques (2013) examined contract flexibility and coping with uncertainties in a single hospital that was developed as a PPP project. Because we were especially interested in the social interaction taking place in the practice of dealing with uncertain situations additional to the formal rules, we chose to focus on the practice of a particular case (see also Gustafson 2017) and come to know it well: "an empirical inquiry that investigates a contemporary phenomenon (the 'case') in depth and within its real-world context."

It is a research strategy that concentrates on understanding the dynamics that are present within single settings (Eisenhardt 1989; Flyvbjerg 2006). We particularly studied the practice of a large-scale PPP infrastructure project by looking at what actually happens when coordinating and dealing with variations. Concentrating on a single case instead of multiple cases enabled us to observe all the steps in the variation process in detail and to study the formal and informal modus operandi of the management of the legal, technical, contract, and stakeholder aspects in a trusted environment. The aim was to capture managers' actions as they dealt with variations and to understand how formal and informal procedures facilitated or impeded their resolution in the execution phase of project. Because of the confidential character of the observations and the complex nature of the phenomenon, such depth would not have been possible within a different research approach. This unique case study showed that informal dealing mechanisms are considered necessary in practice in addition to the contract. It also showed what kinds of informal mechanisms are used in practice and how they are used. This knowledge is in itself valuable for consideration in future contracts and for creating favorable conditions to deal with variation in projects in general. Hence, it also forms a start for further research.

\section{A1/A6 Motorway Case}

The case of our study was the A1/A6 motorway extension in the Netherlands. This PPP project is part of a major multiproject public infrastructure program called the SchipholAmsterdam-Almere (SAA) programme. Traffic along this corridor has greatly increased over 
the past 15 years, primarily due to economic growth and a growing population in the area. Additional traffic growth is expected due to the expansion plans of the cities of Amsterdam and Almere. The purpose of the SAA program is to improve traffic flow, accessibility, and liveability (i.e., socioeconomic conditions) within the SAA corridor. The A1/A6 project is the biggest and most complex project in this program. The motorway is approximately $23 \mathrm{~km}$ long and is located between the towns of Diemen and Almere Haven. By realizing the project, the capacity of the infrastructure will roughly double. The project involves a total of 70 new civil engineering structures, which include a 60-m-wide aqueduct (Europe's widest); a rail bridge near Muiderberg with a span of $380 \mathrm{~m}$; and an additional bridge adjacent to the existing bridge over the Randmeren (the Hollandse Brug), also $380 \mathrm{~m}$ in length.

The A1/A6 project has a nominal contract value of EUR 1 billion (excluding taxes) and a tenure of 30 years (2012-2042). Rijkswaterstaat (the executive agency of the Dutch Ministry of Infrastructure and Water Management) tendered this project under the third edition of the standard DBFM contract to the service purpose vehicle (SPV) company SAAone. SAAone includes major construction companies such as the German company Hochtief and the Dutch companies of VolkerWessels and Boskalis, as well as the fund management company, the Dutch Infrastructure Fund (DIF). The contract close of the tender was in 2012, while the financial close was in 2013. The latter refers to the point at which all the interlinked conditions mandated through the project contracts, including the funding, were met. The construction activities started in 2013 and are scheduled to proceed until 2020.

The DBFM contract is the key contract between the client and the SPV, where the SPV is responsible for the design, building, financing, and maintenance of the project. The SPV has a financial agreement with financers through syndicated loans. This means that, on the debt side, a group of financers provides finance to the SPV for the implementation and maintenance of the project. The Ministry of Infrastructure and Water Management acts as a guarantor for the financers through a direct agreement with them. The client can repay financing through periodic milestone payments to the SPV if the latter performs according to preset availability and safety specifications.

The actual construction of the project is realized through an engineering procurement and construction (EPC) arrangement through a contract between the SPV and the contractors in the EPC. A separate contract will be signed later for maintenance. The SPV receives equity from shareholders (or sponsors) through equity contribution agreements. Usually, the shareholders are connected to (or the same as) the EPC contractors, which creates a direct relationship between the risk management of the SPV and the EPC. To complete the contract structure, Rijkswaterstaat has administrative agreements with 13 local authorities to guarantee stability in the environment of the project. In addition, several external companies were contracted during the tender phase and the realization phase of the project to support and advise Rijkswaterstaat and SAAone regarding legal, technical, and insurance aspects.

\section{Research Methods and Data Analysis}

As mentioned in the Introduction, the study started with a review of the project management literature regarding dealing mechanisms for variation. We did not include the literature on relational contracting and relational governance, because the DBFM contract type as applied in the Netherlands is not a relational contract. In essence it is a design and construct contract with additions turning it into a combined project delivery and service contract. Interestingly, the case studied evolved to a kind of relational contract with its foundation in a traditional 
contract setting. We were especially interested in how this came about and what happened in practice. This gave us the opportunity to look at the interaction mechanisms that enhanced this evolvement. Relational governance is about the processes and institutional settings in which relationships may evolve. Because we studied the practice in the realization phase of the project, the focus of a project is then more on management than on governance. Most governance literature stays at a high level to look into phenomena. We wanted to go a step deeper and therefore especially focused on (relational) project management and related literature.

Data were gathered through a combination of archival research into the project history, observations, and semistructured interviews in the period of September 2016 to February 2017. A case study protocol was used to carry out data collection (Eisenhardt 1989; Yin 2014). To construct validity (Creswell 2013; Yin 2014), information was gathered from all available sources to understand the phenomenon within the context of the entire project. The archival research comprised the DBFM project and the contract documents, including the maps and drawings. Additionally, annual reports, newspaper articles, organizational documents, and reports of the client and the SPV backbone companies were studied. Additional information from memos, minutes of meetings, and contract amendments provided insights into the playing field of variations. Access was granted to all the digital sharing tools between the authority and the SPV and, therefore, to all variations and contract amendments, and to all the minutes of contract and change meetings after financial close.

To gain a better understanding of the mechanisms described in the documents, 21 semistructured interviews were conducted with a diverse group of people from different organizations and backgrounds, among them directors, contract and project managers, engineers, advisors, and lawyers. In this study, client representatives were grouped as contracting authority practitioners (CAP1-CAP11), while SPV practitioners were classed into 10 groups (SPVP1-SPVP10). Organizational organograms were used to make a first selection of interviewees. This selection was done together with the contract manager of the project. A brief introduction to the research objectives and the interview questions was provided to the interviewees via email 1 week before the interview. All interviews were conducted in face-to-face meetings of about 1.5-2 $\mathrm{h}$ by the first author. In some cases, the researcher invited two contract managers to the same interview to encourage further discussion. The Appendix presents the interviewees and interview questions.

To gain further insight into the actual modus operandi, three different kinds of participant observations were carried out by the researcher during a 7-month research period: site visits, contract meetings, and informative visits to the offices of the client and the SPV. Informative questions were asked to several members of the SAA team throughout the complete period of observation. The site visits helped the researchers to understand the issues encountered during the execution of the project and the difficulties arising from these issues. The visits to the client and SPV offices were helpful to understand the relational networks within which the different managers worked.

Additionally, multiple authority-SPV contract meetings, authority-SPV variation meetings and internal authority meetings were attended. In these meetings, the observation focused on various aspects, such as the mechanisms used to deal with variation, styles, processes used to find solutions and interactions of different managers to elaborate; discuss; solve problems; and allocate responsibilities for the solutions. Detailed sketches of these meetings were recorded, similar to Shipton et al.'s (2014) "vignettes," to represent relationships between 
organizations and actors. The atmosphere, modes of communication, and flexibility of the actors were noted during and analyzed directly after the meetings. Simultaneously, feedback was received from contract managers and, as a result, suggestions for improvements in the dealing mechanisms were incorporated into practice so that their effects could subsequently be observed.

According to Yin (2014), a data management strategy is imperative in case study research. An Excel spreadsheet was used to organize and conduct the data collection. This sheet included objectives; relevant readings; and data collection procedures, such as sources of data, contact names, and case study questions. As suggested by Nowell et al. (2017), the researchers familiarized themselves with the data while all files were named with a unique identifier of a source specific to the case. Qualitative data were captured in various forms, including records of observations, transcripts of interviews and meetings, archival documents, multimedia, sketches, maps, drawings, and photographs.

The analysis of all the data was done by way of coding. First the researchers produced initial codes with attributes to differentiate among the different ways of dealing with contract variations based on the studied literature. The data were identified, organized, and indexed relative to these themes. Second, the miscellaneous coded data supported new themes, resulting in a second consistent workable set of themes and codes. Third, we bundled themes into specific dealing mechanisms and related the codes accordingly. This method resulted in the following categories of dealing mechanisms: contract provisions, human relationships, relational governance, digitalized tools, professional knowledge, and actor competences. Contract provisions refer to DBFM agreement articles; human relationships include personal relationships between parties. Relational governance refers in this study to the project management systems in the organizations. Digitalized tools refer to shared IT systems. Knowledge means tacit and explicit knowledge, while actor competences refer to the skills of the project participants. The findings for each category of dealing mechanisms are discussed below.

\section{Results}

The results are presented in this section according to the categories of dealing mechanisms as described above.

\section{Contract Provisions}

The Netherlands has no specific law for PPPs. The Dutch DBFM model agreement complements certain sections of the Dutch civil code with specific contract clauses. For example, the standard model DBFM contract declares that "with respect to the occurrence of unforeseen circumstances, parties agree that they have willingly and wittingly entered into this long-term Agreement and that the mechanisms that are included in this Agreement are already intended to deal with the consequences of any possible unforeseen circumstances that may arise." This clause thus stipulates that parties cannot ignore variations that occur over the long life span of a project. In addition, it acknowledges that the standard DBFM contract is incomplete. Therefore, parties agree to the need to renegotiate provisions for dealing with variation. On this point, SPVP1 mentioned that "circumstances can always arise: there are known knowns, known unknowns and unknown unknowns at the time of signing. We add new clauses when there is a need for variation on the physical asset. This provision provides 
flexibility, accepting uncertainties under our law." CAP1 stated that "there are unknowns in the project, and one cannot be accountable for these unknowns. We act reasonably and fairly regarding our law."

The process of dealing with variation takes place within the boundaries set by the agreement. Regarding this, the agreement can be seen as a foundation for this process. CAP1 added "The DBFM agreement is applied under Dutch civil law with a Standard Contract form. It has specific rules and regulations for contract application and progress of variations (change procedures, changes in law and dispute resolution). For example, when a physical asset has a variation, contract clauses explain how compensation can/should be achieved, who has the responsibility, and allocation of risks under variation. Provisions of Contract comprise a foundation and explain who will take which action."

The provisions in the standard DBFM agreement specify features and characteristics of variation, information exchange, and each party's responsibility during the renegotiation process. These provisions have an important consequence for the allocation of risks under variations. Provisions that deal with variations include, for example, the change procedure (Article 13 and Schedule 5) and the dispute resolution (Article 21). The change procedure includes the right of each party to propose changes. Change is characterized as a "contracting authority change" and/or as a "contractor change." There are no limits to the size of variation that the government may require. The change procedure is further elaborated in "Schedule 5 Changes," which contains the formal change management process of the authority and the private party, to be agreed upon by the partners. Once agreed by both parties, this process is documented as an amendment to the initial contract. In this process, the private party has to provide full details of the costs and timing that will occur when implementing the variation. The types of provisions are designed to promote win-win outcomes by identifying compensation events and to regulate the process of renegotiation. Parties agree on how the variation will be implemented based on this procedure.

An expression of the contract provisions mechanism of the Standard DFBM contract is illustrated in a statement made by CAP4 during an interview: "We use the contract as guidance. We follow Article 13 and Schedule 5 of the DBFM contract for the variation process. [...] When a change occurs, we add new clauses or subclauses to our output specifications and payment schedule. [...] We use written rules as a complementary mechanism to our relationship." But CAP10 also explained that "If there is a big shock, we should be able to put in place a mechanism to handle it, which should be the contract. There is a need for managers to have extensive knowledge about the contract clauses."

In the DBFM standard contract, the distinction between the contracting authority and the contractor's view of change is a significant factor with respect to action, and it explains the way changes are proposed. The change procedure differentiates between "small changes" (below a certain financial threshold) and "other changes." In Schedule 1 of the standard model DBFM contract, small changes are explained and a threshold has to be decided on between the client and SPV during contract close. In the A1/A6 project, an extra category of very small changes was added during the construction phase for practical reasons, which refers to changes that do not have any financial consequences for the project. During an interview, CAP4 explained that "we added this formality to reduce complexity and the number of changes; some changes are too small, have no financial consequences, but still take time to manage." 
For small variations, the contractor must respond to the change request made by the contracting authority within 10 days. For big changes, they have 20 days. However, in practice, we observed that these boundaries are not considered very important to either party. The focus is on the overall availability date for completion rather than these response dates, which means a response is given as soon as possible in practice. If the work is not finished by the availability date, the SPV will receive the completion fee later than envisioned. According to SPVP6, "We are forced to be very quick in our response to the changes, because the availability date is very close, so we take a collaborative approach to changes."

The contract article that was used most to deal with variation was Article 13.1e: "If the contractor can demonstrate to the contracting authority that change has had an adverse effect on the risk profile of the work or on the financers then the contractor must receive a guarantee that the contracting authority will pay compensation for or bear the additional risks." According to CAP7, "This article is important when tensions occur around benefit sharing [...] Financiers are likely to see variations as a source of risk. However, in some circumstances, we help [our contractor] to solve problems caused by change, bearing the additional risk."

\section{Human Relationships}

One of the aspects that was mentioned most frequently during the interviews was that relationships are more predominant than contractual terms when dealing with variations. There appears to be a strong need for relational mechanisms additional to the fixed rules. In this respect, the new business strategy (Market Vision) of Rijkswaterstaat, "Working with the Market," was frequently mentioned. In January 2016 (during the implementation phase of the A1/A6 project), this strategy was mutually agreed on by Rijkswaterstaat and several other client organizations and contractor organizations as a way of doing business together and dealing with problems encountered in practice through more collaboration.

The Market Vision aims to create a better atmosphere and more value for society by encouraging all parties to collaborate closely. By increasing openness between the public client and the contractors through the sharing of knowledge and by stimulating cooperation, it is expected that changes can be dealt with in a more effective manner by both parties, and added value can be generated by cooperation, rather than losing value through contractual battles. According to CAP9, "We apply the Market Vision to create synergy with our private partners. When we deal with variations, we use the contract as a basis, but we give our relationships a more important place in the life cycle of the contract." CAP10 explained that "Unexpected changes can cause tensions, but being aggressive toward each other does not bring any gains. [...] We do not tend to go to our lawyers to solve issues (avoiding disputes)."

Workshops were regularly organized to develop relationships, to gain trust and create openness, and to discuss specific issues or events. These methods proved successful: "After some negotiations we got a pre-order to realize a new design for the Zilverstrand [a particular part with a small beach] that had to be checked by all seven stakeholders. [...] We organized it as a design studio, with a plan and a schedule meant to help us to come to an agreed design. We started in October 2015, and the agreed design was realized in March 2016" (SPVP9).

It was also found that the better the contracting partners know each other, the more willing they are to manage changes in a relational way. This applies especially to the contract 
managers, as mentioned by CAP8: "In this agreement, our contract manager has a very good personal relationship with the SPV counterpart; being friends [...], if managers do not get on, the end result will be no problem-solving." SPVP10 indicated that "We do not rely solely on a rigid formal contract mechanism or formal arrangements. I can call my counterpart anytime to discuss any event, like friends would do, to be more effective." Most of the interviewees indicated the importance of being open to each other: "We exchange our thoughts on pros and cons while managing changes. It is very important to understand each other's interest while dealing with change" (CAP11). Similarly, SPVP6 indicated that "We are transparent with each other and this strengthens our trust. [...] We can think in a cooperative way and understand each other; information flows from one party to another party while dealing with changes." The results indicate that trust and openness facilitate cooperation, and vice versa, and allow for the effective solving of unexpected problems. This kind of openness also became visible in the seating arrangement during the meetings between the SPV and the client: the various participants sat next to each other rather than in their own groups, and this setting arrangement evolved naturally over time.

\section{Relational Governance}

The governance structure was set up at the beginning of the project but evolved during the project execution. The authority used a standardized integrated project management (IPM) model as their organizational structure, which acknowledges the integration of different management functions (project manager, stakeholder manager, technical manager, contract manager, and manager of information and control) into a single integrated project team. The IPM model provided an important mechanism to manage variations. When a change occurred, it was discussed with all team members of the IPM team, which ensured integrated information flow, coordination, and transparency of the issues. During the interviews, CAP5 pointed out that "This model can be illustrated as the firm's philosophy. [...] Under a significant event, the IPM model provides an effective way of communicating and understanding different interests." CAP3 added to this that "the lack of formal hierarchy between managers from different disciplines allows for a speedy flow of information."

Working with the IPM model also regulated the counterparts in the various parties. The SPV attempted to mirror this model in its own governance structure. The business plan for the project included a communication matrix, which lays out who does what, and explains who will meet with whom during change management. According to the matrix, the client project manager was the counterpart of the chief executive officer (CEO) of the SPV. However, we observed that this initial mirror shifted over time and the contract manager became the counterpart of the CEO, while the project manager became the counterpart of the shareholder alongside the program director. Major issues regarding changes were discussed and actions were decided on this level.

The SPV organization structure also demonstrated integrated management of several organizational units. Their organization was divided into three parts: ground works, civil works, and design work. As SPVP1 explained in an interview, "The SPV and EPC Company have become very large; we have employed thousands of people from different backgrounds in a short time. Coordination is challenging. [...] It is people management. Collaborative relationships help with the daily management of variations. Also, a flexible organization structure helps coordination during the variations process." Organizational flexibility was regularly mentioned as a significant factor in the variation process. According to one interviewee, in such a large organization, "We should be more flexible in the roles during the 
process of management. Better understanding of the other's contribution by all team members is important when dealing with variations" (SPVP4). SPVP5 added to this that "more integration brings effective responses to the events."

\section{Digitalized Tools}

Information technology was heavily used in the variation processes of the A1/A6 project. The SPV created an "information cloud" to coordinate information about variations. Most of the information used to make decisions was stored digitally in this cloud. This presented a single and coordinated information tool that enabled data sharing and facilitated coordination between actors. It is interesting that this information cloud was also made accessible to the authority.

The standard Request for Change (RfC) tool was used by the authority to follow the variation process in chronological order. This RfC tool was adjusted to the contract provisions of the variation management procedure in the DBFM contract, and as such supported the decisionmaking process. Thus, the RfC tool acted as the central database with regard to variations for the client. Every variation had a serial number and was included in the variation list data. It was observed that this list comprised big/small/very small variations and was updated every week in the system. Many interviewees highlighted the importance of this tool. According to CAP1, "It is an easy way to follow the steps of the variation process, control, budget, and time. This also makes it easy to visualize all variations." CAP10 explained the importance of feedback loops in this tool, to anticipate, resolve, and approve variation. According to CAP2, "It is the quickest way to see and respond to changes. This tool improves our performance."

Relatics and Think Project tools (both cloud systems for sharing data) were used as the central information database for the contract and thus formed an information backbone for the variation process on the SPV side. A variety of data were linked to this database, such as designs, plans, output specifications, contract documents, International Organization for Standardization (ISO) forms, manuals, and maps. It was observed that when a change occurs, there is a need to update documents related to the variation. CAP3 indicated that "the SPV provided login details for Relatics and the Think Project. This creates openness between us and the SPV which also strengthens our relationship." According to SPVP3, "shared access tools support our cooperation strategy giving clarity to hundreds of pages of formally written contract." Both parties maintained good record keeping using these tools. Any variation was recorded and clearly documented by both organizations. It was observed that the cloud system fostered integration and collaboration between actors.

\section{Professional Knowledge}

The observations indicate that the professional knowledge that is available within the project environment is an important mechanism during the variation process. The authority ensured that the IPM team understood the PPP contract provisions very well, as did the SPV for its contract management team. It was observed that expertise was consciously combined with explicit knowledge (documented information) in both organizations. During an interview, SPVP2 pointed to the Spoorbrug Muiderberg Bridge on the map and stated, "We use the information that is available in our parent organizations. We have been building these bridges for 100 years; we know best what we are doing. Our experience helps us with the contractual variation process. Also, we are familiar with coordinating all interfaces and risk under 
variations." Another example of knowledge exchange was provided by SPVP7: "Involving an international partner brings positive opportunities, due to their extensive knowledge of the correct way to respond to the changes in PPP projects all around the world."

Experience and understanding of the contract appeared to be very important factors in recognizing and managing the network of dependencies in the contracts. During several meetings about variation, it was observed that the managers checked all dependent (and sometimes conflicting) variables in the key contracts (financial contracts, stakeholder contracts, etc.) based on their respective experience. According to CAP6, "The complex nature of PPP type contracts creates a need for technical, financial, and legal knowledge of related contracts to deliver project imperatives on the contract variation process." SPV3 mentioned that "In our project, the contract manager of the client is extremely knowledgeable, which helps him to understand issues, and at the same time is able to consider financial constraints or technical challenges, which is unique for PPPs." Additional financial and technical knowledge was gained from specialist advisors if necessary. According to SPVP3, "Our lender technical advisors helped us a lot with regard to dealing with changes, because they have experience from all over the world. They acted as a bridge between the bankers and us. Without good lender advisors, very few new loan agreements can be signed."

The SAA program of Rijkswaterstaat also used a strategy of sharing experiences across projects within the entire program. Daily informal face-to-face meetings were organized and the client organization provided its employees with opportunities to attend workshops on PPP contracts, performance, risk, and variation management in order to develop their knowledge on these specific types of contracts. During an interview, CAP9 suggested that "Intraproject knowledge creation and learning was explicitly used as a management strategy in the SAA program." CAP9, from the adjacent A6 project, indicated that "The A1/A6 project contains extensive knowledge. This information flows to my team.” The SPV parent organizations also provided in-house and external training programs to managers to improve their knowledge with regard to PPPs and infrastructure projects.

\section{Actor Competences}

The last mechanism relates to a wide range of competences of the actors, which vary from hard to soft skills. During an interview, SPVP8 mentioned the importance of competence, adding "Our PPP managers who are dedicated, well aware of the environment and contract network, with the competence to build relationships, contribute most while dealing with variations." CAP11 stated that "Our biggest variation (i.e., the amendment of the new Spoorbrug Muiderberg Bridge) [...] cannot be compared to any DBFM solution. It is not copied from any other project. Having leadership, social, and communicative skills are highly important in our relationships with the SPV, as it helps us to find unique solutions when there is a big event."

Tensions rose during the negotiation of big events, especially in relation to funding and financial discussions. Power and dominance play a role when discussions focus on the root cause of issues and how they will affect the financial model. The competences of the contract managers on both sides appeared to be especially important in handling these tensions using leadership skills and openness in discussion. CAP5 explained that "The managers need to know how to act in dynamic situations. Social skills are very important for public managers, for example, conversations being neither too formal nor too informal. There should be a 
balance between the interests of public and private." SPVP5 added that negotiation skills such as "verbal communication and facial expressions and emotional control are important for our interests, also in discussions about problems caused by variations." It was considered especially important for PPP actors "to have the necessary leadership and communicative skills ... to be effective in variation management and to deliver value for money to society" (CAP8). This was also valued by SPV, as indicated by one interviewee, who said that "we are very lucky that our client organization is well aware of our binding related contracts to DBFM" (SPVP4).

\section{Summary of the Results}

The results of the study confirmed that contract provisions are generally written ex ante and change over time through the addition of new clauses or subclauses, or by removing clauses ex post. Therefore, the contract is continuously adapted to reality by renegotiations (Cruz et al. 2014; Hart 2017; Xiong and Zhang 2014). The Dutch DBFM standardized contract, as used in our case, was actually designed to be incomplete due to the impossibility of specifying every element ex ante, and in this way it allows for the renegotiation of provisions. The case also demonstrates that several dealing mechanisms were used and developed to cope with variation in practice additionally to the ex-ante contract provisions. The different mechanisms for dealing with variations as observed in the case study and described in this section are summarized in Table 1 .

\section{Discussion}

This study observed the daily real-life practices of dealing with variations in the context of a PPP project. Many of the mechanisms as identified in the literature are reflected in our case findings. Contract provisions are not only an important mechanism for dealing with variations in PPP coordination but are seen as an essential foundation to the process. However, the case also revealed that projects do not or cannot rely solely on contract provisions. In line with the findings of Song et al. (2018) and Xiong and Zhang (2014), the results show that PPPs offer incentives to all partners not to end the collaboration and stimulate parties to conduct renegotiations and attempt to resolve variation issues caused by project dynamics. The foundation of this incentive is the principle of reasonability and fairness, guaranteed by the contract provisions. This principle means that if one cannot reasonably foresee an issue or its consequences, one cannot be held responsible and/or accountable. Reasonability and fairness (good faith) play a noteworthy role in the Dutch legal system and prove to have a major influence when dealing with variations. Relying on the legal guarantee of fairness, parties want to act reasonably when dealing with variations during the implementation period beyond the ex-ante allocated risks. They want to deliver the best value and obtain long-term future benefits.

As also indicated by Brown et al. (2015), relational dealing mechanisms are an important addition to the contract for handling variations. The complementary character of relational mechanisms allows partners to be more engaged and act according to the spirit of a contract rather than the letter. The contract might stay in the drawer, only being taken out in exceptional situations. The case study showed that relationship practices are more predominant than contractual provisions when dealing with variations. In line with the literature on incomplete neoclassical contract forms (e.g., Klijn and Koppenjan 2016; Hart 2017), the case shows that actors mainly consult contractual agreements for guidance and/or 
consider them as a baseline on which to rely. As was also found in the study of Ling et al. (2014), the actual dealing with variation is more dependent on the development of interpersonal relationships, the formal/informal structure of the organization and its flexibility, and the knowledge and skills of the relevant employees. The specific forms of these dealing mechanisms will depend on the type of project, the constitution and character of the project teams, and the context of the project.

The study revealed that partners develop a common approach by translating the contract provisions into their mutual relationships to achieve a certain degree of cooperation. The focus on relationships leads all parties to have a better understanding of each other's interests and to understand the ways that parties perceive the contract terms. In the case study, the pursuit of collaborative relationships was apparent throughout the daily management of variations. For example, partners phoned each other daily and freely, revealing a high degree of communication and transparency; they sat next to each other in meetings, rather than opposite each other with their peers; the parties organized shared interactive workshops to keep relationships active and look for solutions through cocreation; and they also shared login details for digital tools, even when this was not a contractual obligation.

These personal relationships decreased the level of formality of dealing with unforeseen events. Notably, effective and personal communication creates a favorable environment of trust and transparency in the renegotiation process. What helped was that the fairness provision in Dutch Civic Law safeguards parties against potential abuse of trust and transparency and the fact that the client and the contractors involved in the EPC agreed to work according to the Market Vision, in which private entities and authorities are encouraged to act in cooperation. In line with the findings of Hertogh and Westerveld (2010) and Mistarihi et al. (2012), it was observed that highly skilled and experienced project participants make a real (positive) difference when confronted with variations. Both organizations ensured that they had competent managers in the project, who were well aware of the project environment and the network of related contracts in the DBFM, among other aspects.

The study showed that knowledge was considered an important mechanism for dealing with variations. On the one hand, understanding the PPP contract and its procurement is essential to dealing with variations. On the other hand, knowledge development and continuous learning increase the capacity to deal with variations (adaptive capacity). In our case study, activities such as exchange programs between the authority's contract managers from adjacent projects supported the leverage of internal knowledge, improving the public sector's position in the PPP contract. Both organizations were well aware of the importance of knowledge sharing and developing joint knowledge on PPPs. Both organizational managers were involved in constant PPP training during the project, facilitated by their own organization. Furthermore, external companies, such as lenders, technical advisors, and international partners, contributed to knowledge development by bringing in technical advice and international examples of possible solutions. The findings confirm the importance of tacit knowledge gained by experience. However, experience alone is insufficient, if not combined with extensive contractual and financial knowledge.

Furthermore, relationships rely heavily on the communication skills and characters of the actors, with the combination of actors particularly important. This requires a flexible organizational structure in which project participants can be replaced if necessary. Informal 
communication paths rather than formal meetings were intensely used to deal with variations (see also Spiller 2018).

The standard internal integrated project management approach (IPM model) of the authority provided the opportunity for each discipline to align their views and deal with variations in an integrated way. In practice, contractors normally shadow this model in their organizational structure. It might be asked whether this actually is the right governance structure from the contractor's perspective, since they have different roles and responsibilities from those of a public client. It was observed that in practice the predefined structure naturally evolved during the process, with counterparts changing during the project implementation, due to personal relationships and different competences.

Finally, the results indicate that shared digitalized tools contribute to dealing with variations. These tools are designed according to contractual rules and provide an information flow between partners. Digitalized cloud-based tools enabled an easy flow of information between the authority and the private party and encouraged openness and transparency between partners. The shared cloud systems improved the speed of information sharing, enabled the exchange of ideas, and fostered collaborative behavior. This also showed a foundation of trust and created more trust in the project and its partners, which in turn strengthened the relationship between all parties and actors. Additionally, the renegotiation process was expedited and the decision-making process improved by the availability of open and adequate information.

\section{Conclusions and Implications}

The aim of this study was to achieve a better understanding of the range of different contractual and noncontractual mechanisms employed in the coordination of a PPP to deal with contract variations. We chose to study a single case to get in-depth insight into current working practices of dealing with variation in a PPP contract setting. This allowed us to better understand the role of social interaction in the practice of dealing with uncertain situations additional to the formal contract rules. The results indicate that, in addition to contractual provisions, five interrelated and complementary mechanisms are considered important and necessary: human relationships, relational governance, digitalized tools, professional knowledge, and actor competences.

From the findings, it can be concluded that contract provisions governed by formal legal systems are an essential foundation for dealing with variations in infrastructure but need to be adaptive. Contract provisions are written ex ante and are not able to deal with all variations over time. Therefore, they need to be able to be adapted over time by adding new subclauses, removing clauses ex post, or even adding a new contract. This means that the contract should be able to continuously adapt to reality.

To make this adaptability possible, social dealing mechanisms based on interaction between the partners proves to be essential. Based on the principle of reasonability and fairness, Dutch Civic Law creates the opportunity to use different mechanisms rather than solely relying on contract provisions.

Strong relationships support collaborative problem-solving and aligned actions. Transparency and openness between partners, in particular, encourages the development of a positive 
renegotiation atmosphere based on trust rather than formal rules. A mutual vision on how to relate to each other is also important, such as the authority's new market strategy, in which private entities and authorities are encouraged to act collaboratively. In fact, the contract provisions that were observed suggest that the rigidity of a contract can be tackled through ex-post mechanisms when managers are explicitly steered toward this.

It was found that managers with good communication and coordination skills, who are well aware of the project environment and the contractual network, play an important role in dealing with variations. Their expert skills and social competences can lead to adequate solutions being found when unforeseen events occur. Professional knowledge, especially experience from previous projects (e.g., understanding the contract from legal, technical, and environmental perspectives), is a valuable mechanism. Knowledge development and continuous learning increase the capacity to deal with variations. Although some learning across projects was observed, project learning could be made more explicit in public and private organizations that are involved in PPPs.

Transparent digitalized information-exchange tools that structure information can support decision making when dealing with variations. Using a shared cloud system makes it easier to exchange ideas, reduces knowledge asymmetry, increases transparency, and creates trust in the project, which in turn strengthens the relationships between partners. Investing in a good information-exchange structure that supports the competences of the project team is not only important for complex PPP projects but for any infrastructure project.

The predefined organizational structure of PPP projects is also important in building relationships during the initial phase of a project, but should be flexible and able to evolve over time. Counterparts changed roles during the project implementation due to personal preferences and different competences. Relational dynamism complements contractual mechanisms and provides ex-post flexibility.

Like every study, this research has its limitations. Firstly, it was carried out on one specific type of PPP, contracted as a DBFM in the construction industry. Secondly, the study occurred in the Netherlands, within a specific culture and law. Thirdly, we deliberately chose to study a single case in depth, which has to be considered when generalizing the conclusions. Nevertheless, we believe that the results are valuable also for parties dealing with variation in projects outside the Dutch context, but they need to be carefully translated to the specific contexts of the reader.

Future research could focus on other contracts (such as common term agreements) to understand the relationships between SPVs and financers during variations, an aspect that was not addressed in this study. Furthermore, the study could be elaborated to a comparative multicase study. Equivalent cases might be found in other sectors, such as telecommunications, health, or energy, where similar or different mechanisms might be observed.

\section{Data Availability Statement}


Data generated or analyzed during the study are available from the corresponding author by request. Information about the Journal's data-sharing policy can be found here: https://ascelibrary.org/doi/10.1061/(ASCE)CO.1943-7862.0001263.

\section{Acknowledgments}

This research was supported and funded by Rijkswaterstaat and the Deltas, Infrastructure and Mobility Initiative (DIMI) initiated by the Delft University of Technology. Preliminary findings of this case were presented at the sixth International Symposium on Life-Cycle Civil Engineering 2018.

\section{References}

Brown, T. L., M. Potoski, and D. Van Slyke. 2015. "Managing complex contracts: A theoretical approach." J. Publ. Administration Res. Theory 26 (2): 294

308. https://doi.org/10.1093/jopart/muv004.

Creswell, J. W. 2013. Qualitative inquiry and research design: Choosing among five approaches. Thousand Oaks, CA: Sage.

Cruz, C. O., and R. C. Marques. 2013. "Flexible contracts to cope with uncertainty in publicprivate partnerships." Int. J. Project Manage.31 (3): 473-

483. https://doi.org/10.1016/j.ijproman.2012.09.006.

Cruz, C. O., R. C. Marques, and P. Cardoso. 2014. "Empirical evidence for renegotiation of PPP contracts in the road sector." J. Leg. Aff. Dispute Resolut. Eng. Constr. 7 (2):

05014003. https://doi.org/10.1061/(ASCE)LA.1943-4170.0000151.

Cui, C., Y. Liu, A. Hope, and J. Wang. 2018. "Review of studies on the public-private partnership (PPP) for infrastructure projects.” Int. J. Project Manage. 36 (5): 773794. https://doi.org/10.1016/j.ijproman.2018.03.004.

Domingues, S., and D. Zlatkovic. 2015. 'Renegotiating PPP contracts: Reinforcing the ' $p$ ' in partnership." Transp. Rev. 35 (2): 204-225. https://doi.org/10.1080/01441647.2014.992495. Domingues, S., D. Zlatkovic, and A. Roumboutsos. 2015. "Forms of flexibility in transport infrastructure PPPs.” In Proc., 2nd Int. Conf. on Public-Private Partnerships, edited by Z. Zhang, C. A. V. Queiroz, and C. M. Walton, 597-612. Reston, VA: ASCE.

Eisenhardt, K. M. 1989. "Building theories from case study research." Acad. Manage.

Rev. 14(4): 532-550. https://doi.org/10.5465/amr.1989.4308385.

Eurostat. 2016. The statistical treatment of PPP contracts: Manual on Government Deficit and Debt. Brussels, Belgium: Publications Office of the European Union.

Flyvbjerg, B. 2006. "Five misunderstandings about case study research." Qual. Inq. 12 (2): 219-245. https://doi.org/10.1177/1077800405284363.

Gustafsson, J. 2017. "Single case studies vs. multiple case studies: A comparative study." Accessed February 10, 2018. http://www.divaportal.org/smash/get/diva2:1064378/FULLTEXT01.pdf.

Hart, O. 2017. "Incomplete contracts and control." Am. Econ. Rev. 107 (7): 17311752. https://doi.org/10.1257/aer.107.7.1731.

Hertogh, M. J. C. M., and Westerveld, E. 2010. "Playing with complexity. Management and organisation of large infrastructural projects." Ph.D. thesis, Erasmus School of Social and Behavioural Sciences, Erasmus Univ. of Rotterdam.

HM Treasury. 2012. Standardization of PF2 contracts. London: Stationery Office. 
Iossa, E. 2015. "Contract and procurement design for PPPs in highways: The road ahead." Econ. Political Ind. 42 (3): 245-276. https://doi.org/10.1007/s40812-015-0014-5. Javed, A. A., P. T. I. Lam, and A. P. C. Chan. 2014. "Change negotiation in public private partnership projects through output specifications: An experimental approach based on game theory." Constr. Manage. Econ.32 (4): $323-$

348. https://doi.org/10.1080/01446193.2014.895846.

Khan, K. I. A., R. Flanagan, and S. L. Lu. 2016. "Managing information complexity using system dynamics on construction projects." Constr. Manage. Econ. 34 (3): 192-

204. https://doi.org/10.1080/01446193.2016.1190026.

Klijn, E. H., and J. Koppenjan. 2016. "The impact of contract characteristics on the performance of public-private partnerships: Results from a survey among PPP projects in The Netherlands." Publ. Money Manage. 36(6): 455-

462. https://doi.org/10.1080/09540962.2016.1206756.

Klijn, E. H., and J. M. F. Koppenjan. 2016. Governance networks in public sector. London: Routledge.

Kumaraswamy, M., and M. Rahman. 2006. "Applying teamworking models to projects." In The management of complex projects, a relationship approach, edited by S. D. Pryke and H. J. Smyth. Oxford: Blackwell.

Ling, F. Y. Y., Y. Ke, M. M. Kumaraswamy, and S. Q. Wang. 2014. "Key relational contracting practices affecting performance of public construction projects in China." $J$. Constr. Eng. Manage. 140 (1): 04013034. https://doi.org/10.1061/(ASCE)CO.19437862.0000781 .

Liu, J., R. Gao, and C. Y. C. Cheah. 2017. "Pricing mechanism of early termination of PPP projects based on real option theory." J. Manage. Eng. 33 (6):

04017035. https://doi.org/10.1061/(ASCE)ME.1943-5479.0000556.

Liu, J., P. E. D. Love, J. Smith, M. Regan, and P. R. Davis. 2014. "Life cycle critical success factors for public-private partnership infrastructure projects." J. Manage. Eng. 31 (5):

04014073. https://doi.org/10.1061/(ASCE)ME.1943-5479.0000307.

Mandri-Perrott, X. C. 2009. "Optimising project finance solutions in the water sector: Suggestions for enhanced public private partnership.” Ph.D. thesis, Faculty of Spatial Sciences, Univ. of Groningen.

Mistarihi, A. M., M. S. Al Refai, B. A. Al Qaid, and M. A. Qeed. 2012. "Competency requirements for managing public private partnerships (PPPs): The case of infrastructure projects in Jordan.” Int. J. Bus. Manage. 7 (12): 60. https://doi.org/10.5539/ijbm.v7n12p60. Mouraviev, N., and N. K. Kakabadse. 2015. "Legal and regulatory barriers to effective public-private partnership governance in Kazakhstan." Int. J. Public Sect. Manage. 28 (3): 181-197. https://doi.org/10.1108/IJPSM-09-2014-0116.

National Audit Office. 2018. HM treasury: PFI and PFI2. Report by the Comptroller and Auditor General. London: National Audit Office.

Neto, D. C. S., C. O. Cruz, F. Rodrigues, and P. Silva. 2016. "Bibliometric analysis of PPP and PFI literature: Overview of 25 years of research." J. Constr. Eng. Manage. 142 (10): 06016002. https://doi.org/10.1061/(ASCE)CO.1943-7862.0001163.

New Zealand Government, The Treasury. 2013. Contractual framework for the standard form public private partnership project agreement. Wellington, New Zealand: New Zealand Government, The Treasury.

Nowell, L. S., J. M. Norris, D. E. White, and N. J. Moules. 2017. "Thematic analysis:

Striving to meet the trustworthiness criteria." Int. J. Qual. Methods 16 (1):

160940691773384. https://doi.org/10.1177/1609406917733847.

Rijkswaterstaat. 2014. Model DBFM agreement. Amsterdam, Netherlands: Government of the Netherlands. 
Sarmento, J. M., and L. Renneboog. 2016. "Anatomy of public-private partnerships: Their creation, financing and renegotiations." Int. J. Manage. Project Bus. 9 (1): 94 122. https://doi.org/10.1108/IJMPB-03-2015-0023.

Shipton, C., W. Hughes, and D. Tutt. 2014. "Change management in practice: An ethnographic study of changes to contract requirements on a hospital project." Constr. Manage. Econ. 32 (7-8): 787-803. https://doi.org/10.1080/01446193.2014.915336. Shrestha, A., T.-K. Chan, A. A. Aibinu, C. Chen, and I. Martek. 2018. "Risk allocation inefficiencies in Chinese PPP water projects." J. Construct. Eng. Manage. 144 (4): 04018013. https://doi.org/10.1061/(ASCE)CO.1943-7862.0001457.

Song, J., Y. Hu, and Z. Feng. 2018. "Factors influencing early termination of PPP projects in China." J. Manage. Eng. 34 (1): 05017008. https://doi.org/10.1061/(ASCE)ME.19435479.0000572.

Spiller, P. T. 2018. An institutional theory of public contracts: Regulatory implications. Cambridge, MA: National Bureau of Economic Research.

Taleb, N. N. 2008. The black swan: The impact of the highly improbable (Vol. 2). New York: Random House.

Xiong, W., and X. Zhang. 2014. "Concession renegotiation models for projects developed through public-private partnerships." J. Constr. Eng. Manage. 140 (5):

04014008. https://doi.org/10.1061/(ASCE)CO.1943-7862.0000843.

Xiong, W., and X. Zhang. 2016. "The real option value of renegotiation in public-private partnerships.” J. Constr. Eng. Manage. 142 (8):

04016021. https://doi.org/10.1061/(ASCE)CO.1943-7862.0000843.

Xiong, W., X. Zhao, and H. Wang. 2018. "Information asymmetry in renegotiation of publicprivate partnership projects." J. Comput. Civ. Eng. 32 (4):

04018028. https://doi.org/10.1061/(ASCE)CP.1943-5487.0000763.

Yin, R. K. 2014. Case study research design and methods. 5th ed. Thousand Oaks, CA: Sage Publications.

Zou, W., M. Kumaraswamy, J. Chung, and J. Wong. 2014. "Identifying the critical success factors for relationship management in PPP projects.” Int. J. Project Manage. 32 (2): 265274. https://doi.org/10.1016/j.ijproman.2013.05.004. 
Table 1. Dealing mechanisms

Attributes

- Standard change procedure

- Allocation of initiative

- Classification of variation

- Mutually agreed change management process

- Agreement about information exchange in case of variation

- Compensation arrangement

- Contract adaptability

- Reasonability and fairness

- Having a shared vision on collaboration (the new market strategy of Rijkswaterstaat encourages collaboration)

- Shared workshops to discuss issues or events

- People in key roles knowing each other

- Openness and transparency

- Shared cloud systems used between parties for variation

information

- Coordination between parties

- Shared relatics tool used for contract information

- Standard request for change tool used by the client, adapted to

the agreed change management process

- Influence of authority structure (IPM model)

\section{Refer to}

DBFM articles that present formal

mechanisms to deal with variations

Dealing

mechanisms

Contract

provisions
Personal relationships between managers of SPV and managers of authority
Relationships

Digitalized tools
Digitalized shared IT systems
Relational governance 
- Role and position of project manager and contract manager and their counterparts

- Flexible structure over time

- Integrated management in SPV and EPC (many people and

many suborganizations)

- Contract understanding; awareness of project environment;

technical, legal, and financial knowledge

- Knowledge of key contract structure and relationships (network of contracts)

- Sharing knowledge and learning, combining experience with contract understanding

- Leadership, social, and communicative skills

Personal skills of SPV and authority

Competences

- Competence to build relationships managers

Knowledge

- Conflict handling (especially for contract managers) 
Appendix. Interview Questions

\begin{tabular}{lcc}
\hline \multicolumn{1}{c}{ Organization } & Position & No. of interviews \\
Rijkswaterstaat & Project director & 1 \\
Project manager & 2 & 2 \\
Contract manager & 2 & \\
Stakeholder manager & 1 & 1 \\
Technical manager & 1 & \\
Lawyer & 1 & \\
Technical advisor & CEO & \\
SPV & 1 & \\
CFO & 1 & 21 \\
COO & 2 & \\
Project manager & 2 & 1 \\
Contract manager & 1 & \\
Technical manager & Total \\
Lender technical advisor & & \\
\hline
\end{tabular}

Note: $\mathrm{SPV}=$ special purpose vehicle; $\mathrm{CEO}=$ chief executive officer; $\mathrm{CFO}=$ chief finance officer; and $\mathrm{COO}=$ chief operational officer. 


\section{Interview questions}

Can you give me an overview about your organization and your background?

How would you describe the characteristics of variations?

- What process have you used in variation/change management? How do you deal with unknowns in the A1/A6 project?

- What are the key factors to deal with variations?

Which contract provisions do you use to deal with variations in the DBFM contract?

How does the Dutch legal system influence dealing with variations?

Can you tell me the relational approach between Rijkswaterstaat and SPV?

- Can you tell me any other mechanisms that complement the DBFM standard contract to help you deal with variations?

- What is the new business strategy of Rijkswaterstaat? How does influence dealing with variations?

- Can you give me a specific example of the implementation of the new business strategy of Rijkswaterstaat (Market Vision)?

- $\quad$ Can you explain governance structure of your organization during the implementation phase of the project?

- What project management model is included in the business plan to deal with changes in your organization?

- $\quad$ Can you tell me about your organizational structure and your decision process?

- Can you tell me about the biggest change you managed? What type(s) of mechanism(s) have you used to deal with variations?

- What is the function of knowledge in the change management process?

- $\quad$ Can you tell me how knowledge is shared for the change management process?

- What change management tools are available in your organization?

- What social skills do you consider helpful when dealing with variations? 